\title{
Dietary curcumin and capsaicin: Relationship with hepatic oxidative stress and apoptosis in rats fed a high fat diet
}

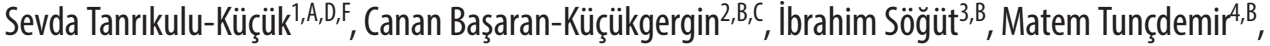

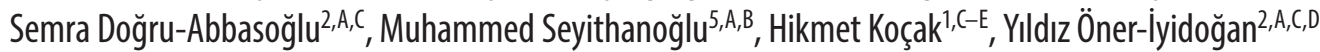 \\ ${ }^{1}$ Department of Biochemistry, Faculty of Medicine, Istanbul Bilim University, Turkey \\ ${ }^{2}$ Department of Biochemistry, Istanbul Faculty of Medicine, Istanbul University, Turkey \\ ${ }^{3}$ Vocational School of Health Services, Istanbul Bilim University, Turkey \\ ${ }^{4}$ Department of Medical Biology, Cerrahpasa Medical Faculty, Istanbul University, Turkey \\ ${ }^{5}$ Department of Biochemistry, Faculty of Medicine, Kahramanmaraş Sütçü Imam University, Turkey \\ A - research concept and design; B - collection and/or assembly of data; C - data analysis and interpretation; \\ $D$ - writing the article; $E$ - critical revision of the article; $F$ - final approval of the article
}

Address for correspondence

Sevda Tanrıkulu-Küçük

E-mail: sevda.kucuk@istanbulbilim.edu.tr

\section{Funding sources}

This work was supported by the Research Fund of Istanbul University, Turkey, project No. 55331 and BEK-2017-24926.

Conflict of interest

None declared

Received on November 2, 2017

Reviewed on December 21, 2017

Accepted on August 9, 2018

Published online on April 15, 2019

Cite as

Tanrıkulu-Küçük S, Başaran-Küçükgergin C, Söğüt I, et al. Dietary curcumin and capsaicin: Relationship with hepatic oxidative stress and apoptosis in rats fed a high fat diet. Adv Clin Exp Med. 2019;28(8):1013-1020.

doi:10.17219/acem/94145

DOI

10.17219/acem/94145

Copyright

Copyright by Author(s)

This is an article distributed under the terms of the

Creative Commons Attribution Non-Commercial License

(http://creativecommons.org/licenses/by-nc-nd/4.0/)

\begin{abstract}
Background. Apoptosis plays a major role in fatty liver disease. High-fat diets are related to the onset of fatty liver disease and hepatic oxidant-antioxidant imbalance. Curcumin and capsaicin are somewhat beneficial in reducing hepatic triglycerides; this is most likely because they are known to downregulate reactive oxygen species (ROS) and apoptosis.
\end{abstract}

Objectives. The aim of this study was to investigate the effects of curcumin and capsaicin on apoptosis through the oxidative effect in an animal model of fatty liver disease.

Material and methods. Male Sprague Dawley rats were fed a normal control diet, a high-fat diet (HFD; 60\% of total calories from fat), a HFD+curcumin (1.5 g curcumin/kg HFD), a HFD+capsaicin (0.15 g capsaicin/kg HFD), or a HFD+curcumin+capsaicin (1.5 g curcumin and $0.15 \mathrm{~g}$ capsaicin/kg HFD). Liver lysate levels of BAX, BCl-2 and caspase-3 were determined via immunoblotting. Caspase-3 activity was measured with a colorimetric caspase-3 measurement kit. Total antioxidant status (TAS) and total oxidant status (TOS) were assayed using commercial kits. The generation of hepatic ROS was measured with fluorimetry. Fragmentation of DNA was detected using the TUNEL method.

Results. High-fat diet caused increased expression of BAX and caspase-3, as well as increased TOS and caspase-3 activity, but decreased expression of BCl-2. HFD+curcumin+capsaicin caused decreased BAX, caspase-3, TOS, and ROS levels as compared to HFD, but increased TAS and BCl-2. A HFD + curcumin + capsaicin also decreased the number of TUNEL-positive cells.

Conclusions. These results suggest that supplementation with curcumin and capsaicin balances the hepatic oxidant-antioxidant status and may have a protective role in the apoptotic process in an HFD-induced fatty liver model.

Key words: apoptosis, curcumin, high-fat diet, fatty liver, capsaicin 


\section{Introduction}

Apoptosis is defined as programmed cell death. It has been reported that several liver diseases, as well as liver injury, induce apoptotic pathways in hepatocytes. ${ }^{1}$ Nonalcoholic fatty liver disease (NAFLD) is associated with obesity and various metabolic disorders, such as steatosis-induced apoptosis. ${ }^{1}$ Hepatocyte apoptosis plays a very important role in liver injury. In order to properly treat liver diseases, the molecular mechanisms and regulating factors of apoptosis must be fully understood. Hepatocyte apoptosis correlates with liver disease severity and can indicate the progression of hepatic fibrosis. ${ }^{1}$

It has been reported that lipid peroxidation products may induce steatosis-induced apoptosis through the activation of the c-Jun N-terminal kinase (JNK) and transcription factor activated protein 1 (AP-1) signaling pathways. ${ }^{2}$ A high-fat diet (HFD) may cause an increase in hepatic lipid content, and also may induce excess generation of reactive oxygen species (ROS). ${ }^{3}$ The accumulation of hepatic fat causes oxidative stress and necrosis, and activates caspase-independent cell death, all of which lead to fibrosis. ${ }^{4,5}$ Among the apoptotic pathways, oxidative stress plays the most important role in NAFLD by facilitating ROS generation. ${ }^{6}$

Curcumin and capsaicin are 2 ingredients of spices commonly used to enhance the taste and flavor of food; in addition, they have been shown to induce several beneficial effects in the pathogenesis of fatty liver disease. ${ }^{4,7,8}$ Curcumin (1,7-Bis (4-hydroxy-3-methoxyphenyl)-1,6heptadiene-3,5-dione, turmeric yellow, diferuloylmethane) is a natural yellow polyphenol extracted from the rhizome of turmeric (Curcuma longa L.; Zingiberaceae). It has been reported to have many positive effects on health, as it has anti-inflammatory, anti-cancer and anti-hyperlipidemic properties. ${ }^{4}$ Capsaicin (8-methyl-N-vanillyl-6-nonenamide) is a major and very pungent ingredient of red pepper (Capsicum annuum L.; Solanaceae) that has been shown to have some pharmacological uses in pain relief, weight reduction, anti-cancer properties, cardiovascular effects, and gastrointestinal effects. ${ }^{9}$ A few studies have reported the antioxidant and anti-inflammatory potentials of these 2 spices. ${ }^{10,11}$ Again, very limited reports have experimentally demonstrated the antiapoptotic effects of curcumin and/or capsaicin. ${ }^{12-15}$ However, the potential protective role of curcumin and capsaicin on the fatty liver-induced apoptotic process is still unclear. We have recently reported the beneficial influences of dietary curcumin and capsaicin on the reduction of liver fat. ${ }^{8}$ In the present investigation, we specifically focused on elucidating the additive and/or synergistic effect of curcumin and capsaicin in combination on antiapoptotic and anti-inflammatory status in an experimental fatty liver model. Therefore, the aim of our current study is to examine the effects of curcumin and capsaicin on oxidant-antioxidant status and the development of apoptosis in fatty liver disease in rats fed a HFD.

\section{Material and methods}

\section{Animals and diets}

The experimental procedure used in this study meets the guidelines of the Animal Care and Use Committee of the University of Istanbul, Turkey (No. 133/2013). Male Sprague Dawley rats $(217 \pm 12$ g; $n=40)$ were obtained from the Experimental Medical Research Institute of Istanbul University. The animals were housed 4 per cage at room temperature $\left(24-25^{\circ} \mathrm{C}\right)$ and a 12 -hour dark/light cycle with free access to food and water. The rats were randomly divided into 5 equal groups: Group 1 (control group) was fed a normal control diet (standard laboratory chow, $2.6 \mathrm{kcal} / \mathrm{g}$; MBD, Istanbul, Turkey), Group 2 (HFD group) was fed a HFD ( $60 \%$ of total calories from sheep fat, $3.9 \mathrm{kcal} / \mathrm{g}$; MBD), Group 3 (HFD+CUR) received a HFD supplemented with curcumin (Product No. 820354; Merck, Darmstadt, Germany; 1.5 g curcumin/kg HFD), Group 4 (HFD+CAP) was given a HFD supplemented with capsaicin (Product No. J62865; Alfa Aesar, Karlsruhe, Germany; 0.15 g capsaicin/kg HFD), and Group 5 (HFD+CUR+CAP) received a HFD supplemented with curcumin and capsaicin $(1.5 \mathrm{~g}$ curcumin $+0.15 \mathrm{~g}$ capsaicin $/ \mathrm{kg}$ HFD) for a total of 16 weeks. The curcumin dosage was calculated based on our previous studies ${ }^{7}$ and on the study of Ejaz et al. ${ }^{16}$ The capsaicin dose was calculated according to the study of Kang et al. ${ }^{17}$ Body weight and food intake were recorded weekly, and the average daily food consumption for each rat was calculated. ${ }^{8}$ The animals were weighed at the end of the experimental period. Then, they were anesthetized with sodium pentobarbital (50 mg/kg, i.p.), sacrificed by cardiac puncture and their blood was collected into dry tubes. Liver tissues were rapidly removed, weighed, washed in ice-cold saline, and frozen at $-80^{\circ} \mathrm{C}$ until further analysis. For TUNEL staining, liver tissues were fixed in $10 \%$ neutral formalin and embedded in paraffin.

\section{Liver triglycerides and total cholesterol}

Liver tissue homogenate $(10 \% \mathrm{w} / \mathrm{v})$ was prepared in icecold $0.15 \mathrm{M} \mathrm{KCl}$. Tissue lipid extracts were obtained according to the procedure of Folch et al. ${ }^{18}$ Hepatic liver triglycerides (TG) and total cholesterol (TC) levels were measured in lipid extracts with commercial colorimetric assay kits ((triglycerides, GPO-POD Liquid kit and Cholesterol, CHOD-POD Liquid kit; BIOLABO, Maizy, France).

\section{Liver total antioxidant status, total oxidant status and oxidative stress index}

Rat liver tissues were weighed and homogenized in icecold $0.15 \mathrm{M} \mathrm{KCl} \mathrm{using} \mathrm{an} \mathrm{Ultra} \mathrm{Turrax} \mathrm{T18} \mathrm{basic} \mathrm{homogeniz-}$ er (IKA, Wilmington, USA). The homogenate was centrifuged at $600 \times \mathrm{g}$ for $10 \mathrm{~min}$ at $4^{\circ} \mathrm{C}$, and the supernatant was used for the determination of liver total antioxidant status 
(TAS) and total oxidant status (TOS) levels using commercial assay kits (Rel Assay Diagnostics, Gaziantep, Turkey). Tissue TAS and TOS levels are presented as $\mu \mathrm{mol} / \mathrm{L}$. Oxidative stress index (OSI) values were calculated using the following formula: OSI $=($ TOS $/$ TAS $) \times 100 .{ }^{19}$

\section{Determination of reactive oxygen species levels}

Liver ROS generation was measured using a fluorimetric assay with dichlorofluorescein. ${ }^{20}$ In this assay, $1 \mathrm{mM}$ 2',7'-dichlorodihydrofluorescein diacetate $\left(\mathrm{DCFH}_{2}\right.$-DA, Product No. D 6883; Sigma-Aldrich, St. Louis, USA) diffuses passively into the cells, and the $\mathrm{DCFH}_{2}$-DA acetate groups are cleaved by intracellular esterases, yielding intracellular 2',7'-dichlorodihydrofluorescein $\left(\mathrm{DCFH}_{2}\right)$. Reactive oxygen species oxidize $\mathrm{DCFH}_{2}$ to form a fluorescent compound, 2',7'-dichlorofluorescein (DCF), which can be measured using a microplate fluorimeter (Fluoroskan Ascent FL; Thermo Fisher Scientific, Inc., Waltham, USA) with an excitation of $485 \mathrm{~nm}$ and an emission of $538 \mathrm{~nm}$. Results are expressed as relative fluorescence units (RFU).

\section{Hepatic caspase-3 activity}

Liver tissue samples were homogenized $(1 / 10 \mathrm{w} / \mathrm{v})$ in lysis buffer (250 mM HEPES, pH 7.4, 25 mM CHAPS, $25 \mathrm{mM} \mathrm{DTT}$ ) and then centrifuged for $20 \mathrm{~min}$ at 3,000 $\mathrm{rpm}\left(+4^{\circ} \mathrm{C}\right)$. Supernatants were collected and centrifuged twice at 14,000 rpm for 15 min each. ${ }^{21}$ A colorimetric caspase-3 measurement kit (Sigma-Aldrich) was used to determine caspase-3 activities in the supernatant. This kit is based on the hydrolyzation of acetyl-Asp-Glu-Val-Aspnitroanilide by caspase-3, which generates p-nitroaniline (pNA). The absorbance of pNA was measured at $405 \mathrm{~nm}$, and results are expressed as $\mu \mathrm{mol} \mathrm{pNA} / \mathrm{min}$.

\section{TUNEL assay}

The terminal deoxynucleotidyl transferase-mediated dUTP nick end-labeling (TUNEL) assay is a technique that detects DNA fragmentation by labeling the terminal end of nucleic acids. This assay has also been used to confirm apoptosis of liver tissues. Herein, the TUNEL assay was performed as previously described ${ }^{22}$ with the ApopTag Peroxidase In Situ Apoptosis Detection Kit (S7101-KIT; Merck Millipore, Burlington, USA). Briefly, each liver tissue slide was deparaffinized, rehydrated and treated with proteinase $\mathrm{K}(20 \mathrm{mg} / \mathrm{L})$ for $15 \mathrm{~min}$ at room temperature. The endogenous peroxidase was inhibited with $3 \%$ hydrogen peroxide for $5 \mathrm{~min}$, and then the slide was incubated with the TUNEL reaction mixture (containing terminal deoxynucleotidyl transferase $(\mathrm{TdT})$ ) in a humidified chamber at $37^{\circ} \mathrm{C}$ for $1 \mathrm{~h}$. Then, the 3,3-diaminobenzidine (DAB) chromogen was applied, and methyl green was used for counterstaining. The TdT was omitted from the reaction mixture as a negative control.

\section{Apoptotic index}

Marked apoptotic cells were counted under high-power fields $(\times 40)$ with a light microscope (Leica DM2500; Leica Camera AG, Wetzlar, Germany). Cell nuclei stained with methyl green were considered to be healthy, while those with brown nuclear staining were considered TUNEL-positive. All TUNEL-positive cells were counted in 15 randomly selected fields by a researcher who was blinded to the identity of the samples. The average number of cells per unit area for each set of specimens in each group was calculated and compared.

\section{Liver caspase-3, Bax, and Bcl-2 protein expression}

To detect Bax, Bcl-2, and anti-active caspase-3, livers were homogenized $(10 \% \mathrm{w} / \mathrm{v})$ in a buffer containing $50 \mathrm{mM}$ Tris- $\mathrm{HCl}$ (pH 7.4), $150 \mu \mathrm{M} \mathrm{NaCl}, 2 \mu \mathrm{M}$ ethylenediaminetetraacetic acid (EDTA), 8.7\% glycerol, 0.5\% sodium deoxycholate, $1 \%$ Triton X-100, 0.1\% sodium dodecyl sulfate (SDS), and protease inhibitor cocktail (P8340; Sigma-Aldrich). The samples were then centrifuged at $600 \times$ g for $10 \mathrm{~min}$ $\left(+4^{\circ} \mathrm{C}\right)$, and then the supernatants were collected and centrifuged at $10,000 \times \mathrm{g}$ for $20 \mathrm{~min}\left(+4^{\circ} \mathrm{C}\right) .{ }^{23}$ The total protein content of the supernatant was determined with bicinchoninic acid (BCA) protein assay (Pierce, Rockford, USA). ${ }^{24}$ Equal amounts of protein $(80 \mu \mathrm{g} /$ well $)$ were loaded onto 8-10\% SDS-polyacrylamide gels and blotted onto polyvinylidene (PVDF) membranes (Merck Millipore). Nonspecific binding sites were blocked with 5\% non-fat dry milk in phosphate-buffered saline-Tween 20 (PBS-T), and then the membranes were incubated for $16 \mathrm{~h}$ at $+4^{\circ} \mathrm{C}$ with primary antibodies as follows: BAX (1:200; sc-493; Santa Cruz Biotechnology, Dallas, USA), Bcl-2 (1:200; sc-492; Santa Cruz Biotechnology) and anti-active caspase-3 (1:200; JM-3015-100; MBL Life, Woburn, USA). Then, the membranes were washed with PBS-T and incubated for $1 \mathrm{~h}$ at room temperature with secondary antibody (goat anti-rabbit immunoglobulin (IgG) conjugated with horseradish peroxidase (HRP); 1:5,000; sc-2004; Santa Cruz Biotechnology). Immunoreactivity of the protein bands was detected with enhanced chemiluminescent autoradiography (ECL kit; Amersham Pharmacia Biotech, Piscataway, USA). Protein bands were quantified via measurement of band density with ImageJ software (National Intitutes of Health, Bethesda, USA); the same pixel scale was used for all blots. An internal standard (actin; sc-1616R; Santa Cruz Biotechnology) was used to normalize the values of Bax, Bcl-2 and anti-active caspase-3. ${ }^{24-26}$

\section{Statistical analysis}

SPSS software v. 21.0 (IMB Corp., Armonk, USA) was used to statistically analyze all biochemical parameters. GraphPad InStat DTCG (GraphPad Software, San Diego, 
USA) was used to analyze data collected from the TUNEL method. All variables are expressed as means \pm standard deviation (SD). A one-way analysis of variance (ANOVA) was used to compare all values, while a Levene test was used to assess the homogeneity of the variances. Tukey's test or Tamhane's T2 test were used in cases with overall significance. Apoptotic cell counts of each group were compared using a one-way ANOVA and Tukey-Kramer test. Pearson's correlation test was used to evaluate correlations between variables. Values of $\mathrm{p}<0.05$ were considered significant.

\section{Results}

The weekly food intake of each rat was recorded throughout the 16 weeks of the study. Supplementation of HFD with curcumin and capsaicin decreased daily food intake compared with the control group and the HFD group. However, with the exception of the HFD group, the energy intakes were not significantly different between groups (Table 1). Liver TG $(5.47 \pm 1.45 \mu \mathrm{mol} / \mathrm{g}$ tissue vs $14.2 \pm 3.09 \mu \mathrm{mol} / \mathrm{g}$ tissue) and TC (3.00 $\pm 0.41 \mu \mathrm{mol} / \mathrm{g}$ tissue vs $5.13 \pm 1.00 \mu \mathrm{mol} / \mathrm{g}$ tissue) levels were significantly higher in the HFD group than in the controls. In addition, the augmentation of liver fat appeared to decrease with the individual or combined treatments of curcumin and capsaicin (Table 1).

Hepatic TOS and OSI levels increased in the HFD group compared to the control group ( $\mathrm{p}<0.05$ and $\mathrm{p}<0.01$, respectively), but TOS and OSI levels were decreased with supplementation of curcumin and capsaicin (HFD+CUR+CAP) when compared to the HFD group ( $p<0.01$ for both). In addition, the TAS levels of the HFD $+C U R+C A P$ group were significantly increased over those of the HFD group ( $\mathrm{p}<0.01)$ (Table 2).

Liver ROS generation was not affected by HFD; however, supplementation with curcumin and/or capsaicin reduced ROS levels compared with the HFD group ( $<$ 0.05) (Fig. 1).

The expression of the hepatic proapoptotic proteins BAX and caspase-3 significantly increased in HFD-fed rats compared to those fed a control chow ( $p<0.01$ for both). Supplementation of the HFD with either CUR or CAP led to decreases in BAX and caspase-3 expression; however, only BAX expression was significantly lower than that of the HFD-fed rats for both CUR and CAP ( $p<0.05)$. There was a significant decrease in both BAX and caspase-3 protein in rats fed a HFD+CUR+CAP diet ( $<$ < 0.01) (Fig. 2).

Hepatic caspase-3 activities increased in HFD group ( $\mathrm{p}<0.01$ ); this activity was significantly suppressed in the HFD+CUR+CAP group ( $<$ < 0.05) (Fig. 3).

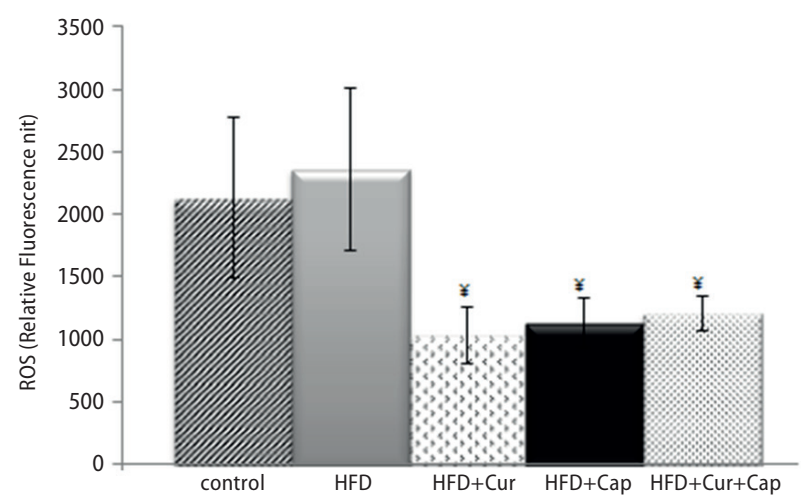

Fig. 1. Hepatic ROS levels in the experimental groups. Values are expressed as mean \pm standard deviation (SD).

$¥ p<0.05$, compared to the HFD group

Table 1. Daily food and energy intake, liver triglycerides (TG) and total cholesterol (TC) levels in control rats and rats fed a high-fat diet (HFD). Values are expressed as mean \pm standard deviation (SD)

\begin{tabular}{|c|c|c|c|c|c|}
\hline Parameter & $\begin{array}{l}\text { Control group } \\
\quad(n=8)\end{array}$ & $\begin{array}{l}\text { HFD group } \\
\qquad(n=8)\end{array}$ & $\begin{array}{l}\text { HFD+CUR group } \\
\qquad(n=8)\end{array}$ & $\begin{array}{l}\text { HFD+CAP group } \\
\qquad(n=8)\end{array}$ & $\begin{array}{c}\text { HFD+CUR+CAP group } \\
(n=8)\end{array}$ \\
\hline Daily food intake [g/rat] & $21.1 \pm 1.25$ & $17.2 \pm 2.10^{\mathrm{a} 3}$ & $13.4 \pm 1.30^{\mathrm{a} 3, \mathrm{~b} 3}$ & $14.5 \pm 2.32^{\mathrm{a} 3, \mathrm{~b} 1}$ & $14.4 \pm 1.82^{\mathrm{a} 3, \mathrm{~b} 2}$ \\
\hline Daily energy intake [kcal/rat] & $54.8 \pm 3.26$ & $68.3 \pm 8.34^{\mathrm{a} 3}$ & $53.2 \pm 5.17^{\mathrm{b} 3}$ & $57.6 \pm 9.23^{b 1}$ & $57.3 \pm 7.22^{\mathrm{b} 2}$ \\
\hline Liver TG [ $[$ mol/g tissue] & $5.47 \pm 1.45$ & $14.2 \pm 3.09^{\mathrm{a} 3}$ & $6.38 \pm 1.76^{\mathrm{b} 3}$ & $4.54 \pm 1.10^{\text {b3 }}$ & $6.09 \pm 0.82^{b 3}$ \\
\hline Liver TC [ $\mu \mathrm{mol} / \mathrm{g}$ tissue] & $3.00 \pm 0.41$ & $5.13 \pm 1.00^{\mathrm{a} 2}$ & $2.45 \pm 0.27^{\mathrm{b} 3}$ & $1.86 \pm 0.51^{\mathrm{b} 3}$ & $2.96 \pm 0.44^{\mathrm{b} 2}$ \\
\hline
\end{tabular}

${ }^{a 1} p \leq 0.05,{ }^{a 2} p \leq 0.01,{ }^{a 3} p \leq 0.001 ;$ compared to the control group.

${ }^{b 1} \mathrm{p} \leq 0.05,{ }^{b 2} \mathrm{p} \leq 0.01,{ }^{3} \mathrm{p} \leq 0.001$; compared to the HFD group.

Table 2. Hepatic total oxidant status (TOS), total antioxidant status (TAS) and oxidative stress index (OSI) in control rats and rats fed a high-fat diet (HFD). Values are expressed as mean \pm standard deviation (SD)

\begin{tabular}{|l|c|c|c|c|c|}
\multicolumn{1}{|c|}{ Parameter } & Control group $(\mathrm{n}=8)$ & $\begin{array}{c}\text { HFD group } \\
(\mathrm{n}=8)\end{array}$ & $\begin{array}{c}\text { HFD+CUR group } \\
(\mathrm{n}=8)\end{array}$ & $\begin{array}{c}\text { HFD+CAP group } \\
(\mathrm{n}=8)\end{array}$ & $\begin{array}{c}\text { HFD+CUR+CAP group } \\
(\mathrm{n}=8)\end{array}$ \\
\hline TOS $[\mu \mathrm{mol} / \mathrm{L}]$ & $17.7 \pm 2.70$ & $22.9 \pm 2.88^{\mathrm{a} 2}$ & $20.8 \pm 2.71$ & $19.7 \pm 1.92$ \\
\hline TAS $[\mu \mathrm{mol} / \mathrm{L}]$ & $1,734 \pm 105.2$ & $1,630 \pm 91.4$ & $1,818 \pm 209$ & $1,698 \pm 58.8$ \\
\hline OSI $[$ arbitrary units] & $1.01 \pm 0.15$ & $1.42 \pm 0.23^{\mathrm{al}}$ & $1.15 \pm 0.20$ & $1.16 \pm 0.13$ \\
\hline
\end{tabular}

${ }^{a 1} p \leq 0.05,{ }^{a 2} p \leq 0.01 ;$ compared to the control group.

${ }^{b 1} \mathrm{p} \leq 0.01$; compared to the HFD group. 

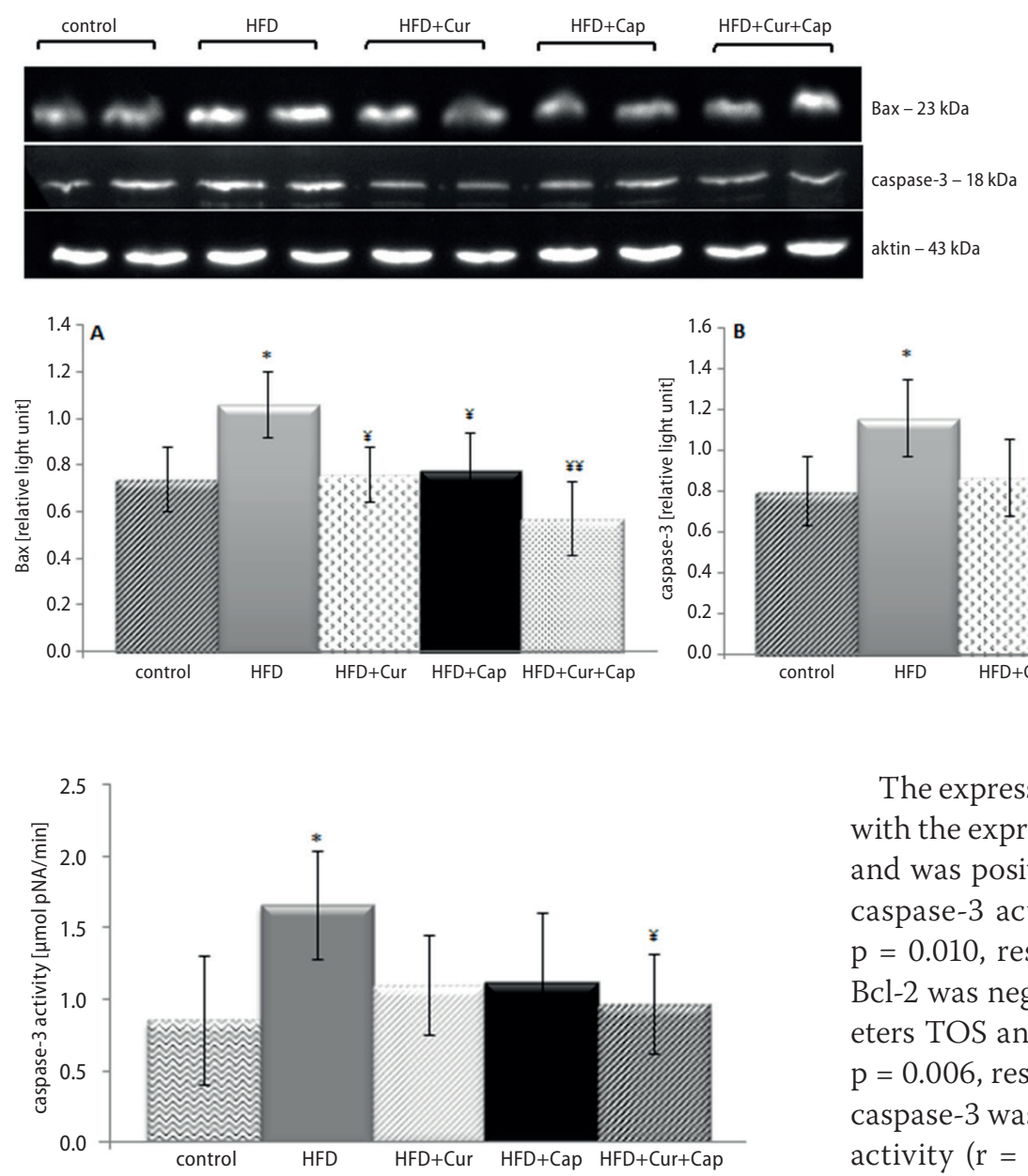

Fig. 3. Hepatic caspase-3 activities in the experimental groups. Values are expressed as mean \pm standard deviation (SD)

${ }^{*} p<0.01$; compared to the control group; ${ }^{*} p<0.05$, compared to the HFD group.

The expression of the antiapoptotic protein $\mathrm{Bcl}-2$ is shown in Fig. 4. The HFD+CAP group had increased Bcl-2 expression as compared to the HFD group ( $\mathrm{p}<0.05)$; however, $\mathrm{Bcl}-2$ expression was not altered by curcumin treatment (Fig. 4).

As indicated in Fig. 5, there were few TUNEL-positive cells in the control group. The number of TUNEL-positive cells significantly increased in the HFD group compared to the controls $(\mathrm{p}<0.001)$. In addition, the number of TUNEL-positive cells in the HFD+CUR+CAP group was similar to that of the control group (Fig. 5E).
Fig. 2. Band density analysis of $\operatorname{Bax}(A)$ and caspase-3 (B) in liver sections of the experimental groups. Values are expressed as mean \pm standard deviation (SD)

${ }^{*} \mathrm{p}<0.01$, compared to the control group; $¥ p<0.05$, compared to the HFD group.
The expression of hepatic BAX was negatively correlated with the expression of hepatic Bcl-2 ( $\mathrm{r}=-0.565, \mathrm{p}=0.004)$, and was positively correlated with hepatic OSI levels and caspase- 3 activities $(r=0.477, p=0.018$ and $r=0.518$, $\mathrm{p}=0.010$, respectively). The expression of antiapoptotic $\mathrm{Bcl}-2$ was negatively correlated with the oxidative parameters TOS and OSI $(r=-0.447, p=0.022$ and $r=-0.528$, $p=0.006$, respectively; Fig. 6A). The expression of hepatic caspase- 3 was positively correlated with hepatic caspase-3 activity ( $\mathrm{r}=0.428, \mathrm{p}=0.029)$. Hepatic ROS levels were positively correlated with the expression of hepatic BAX $(r=0.492, p=0.011$; Fig. 6B) and negatively correlated with TAS $(r=-0.441, p=0.010)$.

\section{Discussion}

A HFD has been shown to aid in hepatic fat storage, which is a symptom of fatty liver disease. ${ }^{27} \mathrm{HFD}$-induced fatty liver disease is thought to be the cause of some metabolic and biochemical disorders as well as hepatocyte apoptosis. ${ }^{6,28}$ Apoptotic cells exhibit various biochemical changes, such as proenzyme activation, protein cleavage or cross-linking, and DNA breakdown. ${ }^{29}$ Oxidative stress plays an important role in inducing apoptosis, as well as in the progression of liver injury. ${ }^{1}$

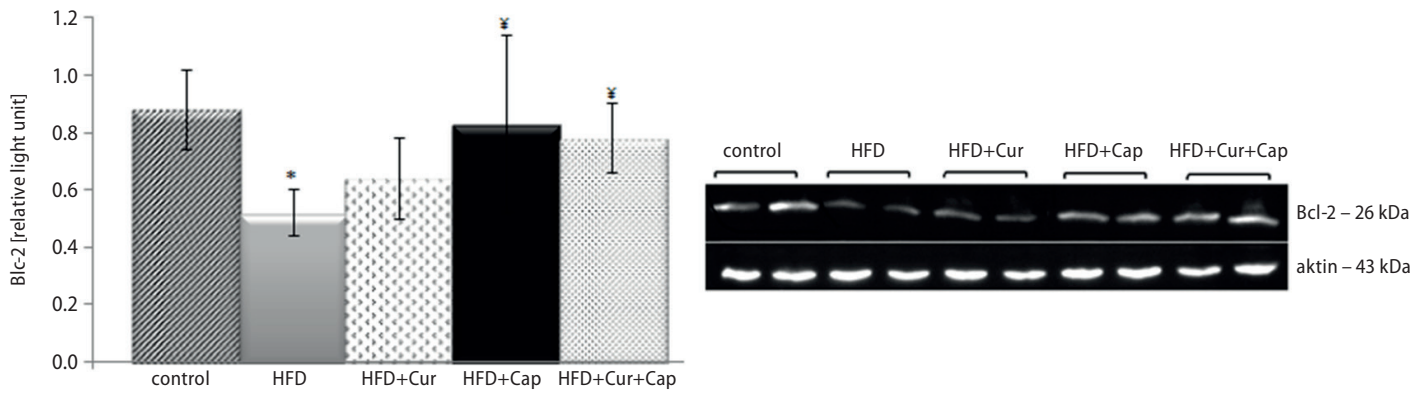

Fig. 4. Band density analysis of $\mathrm{BCl}-2$ expressions. Values are expressed as mean \pm standard deviation (SD)

${ }^{*} \mathrm{p}<0.01$, compared to the control group; $¥ p<0.05$, compared to the HFD group. 

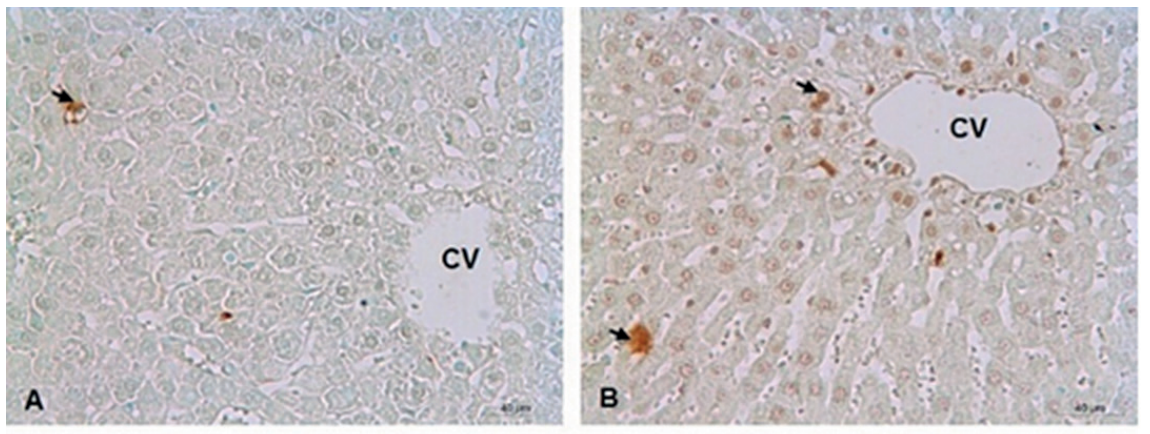

Fig. 5. TUNEL staining results of liver tissue. Control group (A), HFD group (B), HFD+CUR group (C), HFD+CAP group (D), HFD+CUR+CAP group (E), and apoptotic cell numbers in experimental groups (F). Values are expressed as mean \pm standard deviation (SD) ( $\rightarrow$ : apoptotic nuclei). Apoptotic cells were stained brown. Counterstain: methyl green; Bar: 40 m; cv - central vein

* $p \leq 0.001$, compared to the control group; $¥ p \leq 0.01$, compared to the HFD group.
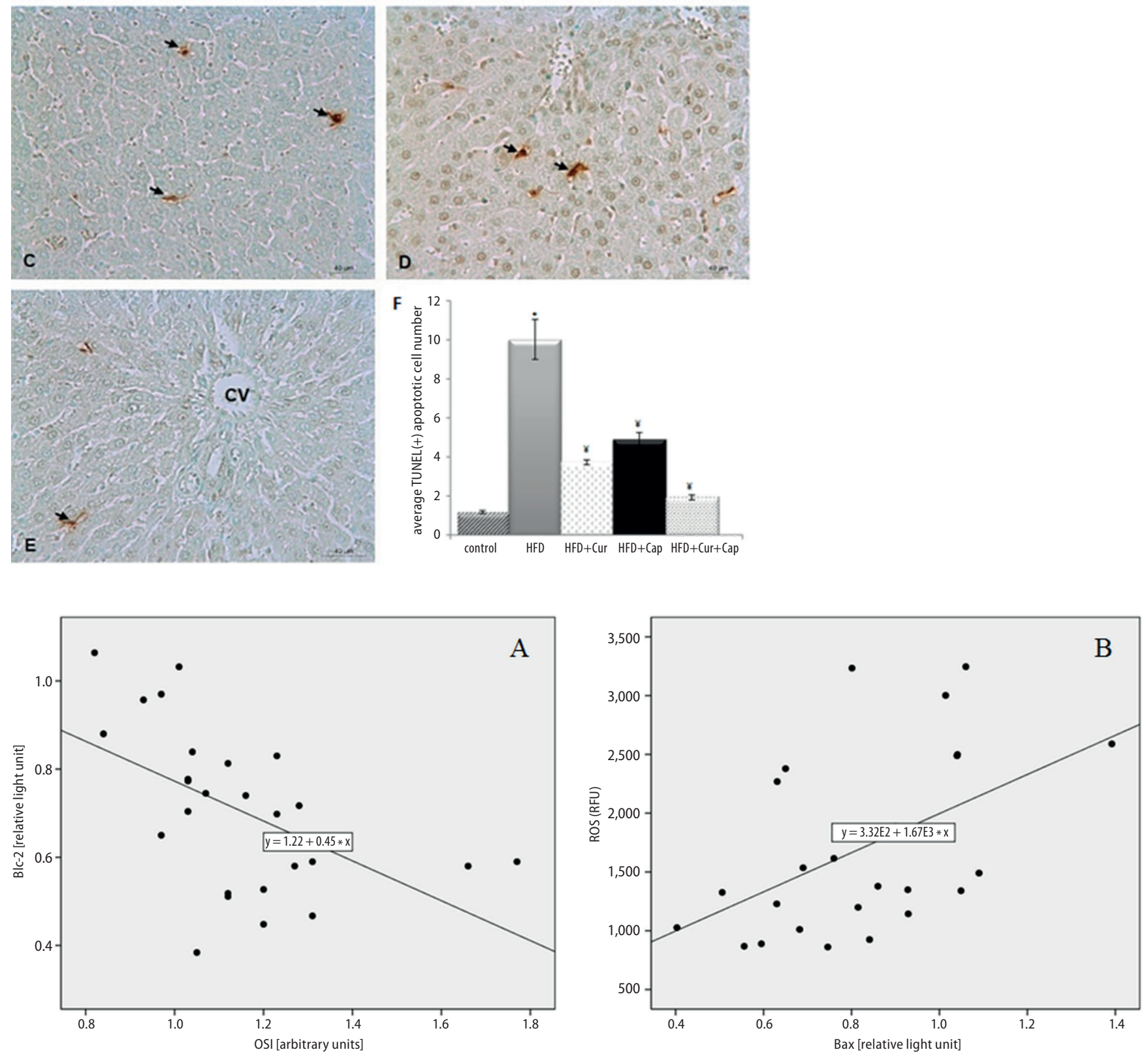

Fig. 6. A - regression between hepatic Bcl-2 protein expression and oxidative stress index (OSI) levels $(n=32 ; r=0.528, p=0.006)$. B - regression between hepatic Bax protein expression and ROS levels in all experimental groups $(n=32 ; r=0.492, p=0.011)$

In the present study, curcumin and capsaicin were administered either together with the HFD or alone. Highfat diet was premixed with curcumin $(1.5 \mathrm{~g} / \mathrm{kg}$ HFD) and/or capsaicin $(0.15 \mathrm{~g} / \mathrm{kg}$ HFD) and the pellets composed were given to the animals. The bioavailability of curcumin was reported to be approx. 60-66\% of the given dose and after 12 days of oral administration of $400 \mathrm{mg}$ curcumin to rats, respectable amounts of curcumin metabolites were present in their tissues. ${ }^{30}$ It was demonstrated that some substances such as alkaloid piperine, a constituent from 
black pepper, increased the serum bioavailability of curcumin by $2,000 \%{ }^{31}$ Furthermore; it was found that the bioavailability of curcumin was increased 7-8-fold when dissolved in oil or mixed with fatty diet. ${ }^{32}$ It was shown that dietary capsaicin administration is rapidly and directly absorbed by the stomach and the intestine. Absorbed capsaicin ranges depend from $50 \%$ to $90 \%$ associated with the experimental model used..$^{33}$ Our experimental diet has been designed in accordance with these studies.

It was recently reported that dietary curcumin and capsaicin have antioxidative and hepatic lipid-reducing effects in rats fed a HFD. ${ }^{8,11}$ However, the effect of curcumin and capsaicin on the prevention of hepatocyte apoptosis in fatty liver disease is not clear. In the present study, treatment with dietary curcumin and capsaicin reduced hepatic lipid levels induced by the consumption of HFD. Rats fed a HFD had a nearly 2.6-fold increase in liver TG accumulation over the controls; however, this level returned to that of the control group when these rats were given curcumin or capsaicin, either individually or in combination.

The expression of the hepatic pro-apoptotic proteins BAX and caspase-3 increased, as did caspase-3 activity, while hepatic anti-apoptotic protein Bcl-2 decreased, in rats fed a HFD. Treatment of combined curcumin and capsaicin reversed these effects. Caspase- 3 is reported to be the most important enzyme that is activated by any of the initiator caspases (caspase-8, caspase- 9 or caspase-10). ${ }^{34}$ Caspase- 3 also induces the cytoskeletal degeneration of apoptotic cells. ${ }^{34}$ In the current study, we measured caspase-3 with biochemical and immunoblotting, and both methods revealed that caspase- 3 was suppressed with supplementation of curcumin and capsaicin combination. These 2 spices may prevent apoptosis by inhibiting pro-apoptotic proteins and by inducing anti-apoptotic progression. This hypothesis has been supported by other researchers. In the study of Yu et al., capsaicin inhibits fibrogenesis by suppressing cell proliferation and activation in cultured hepatic stellate cells (HSCs). ${ }^{35}$ Galaly et al. reported that curcumin prevents liver injury by regulating apoptosis. ${ }^{36} \mathrm{Li}$ et al. revealed that chronic dietary capsaicin prevents fatty liver disease by inducing peroxisome proliferator-activated receptor $\delta$ (PPAR $\delta$ )-dependent autophagy. ${ }^{10}$ Further, Becatti et al. demonstrated that curcumin and capsaicin have inhibitory apoptotic effects, as they increased phosphorylation of ERK in perilesional skin keratinocytes. ${ }^{14}$

Many studies have reported that an increase or decrease in cell death by apoptosis plays an important role in the pathogenesis of many diseases. ${ }^{37,38}$ Apoptotic cells are commonly detected around injured tissue. The TUNEL method determines the number of apoptotic cells and the enzymatic endonuclease cleavage products end-labeling the DNA strand breaks. ${ }^{39}$ In our current study, the HFD group had a significantly higher number of apoptotic cells than the controls. However, the individual or combined treatment with curcumin and/or capsaicin decreased the number of TUNEL-positive cells compared to the HFD group.
Of note, the protective effect of the combination of curcumin and capsaicin on cell death seems to be more effective than when they are used individually.

Recently published data has shown that mitochondrial dysfunction and cellular stress derived from oxidative stress play an important role as risk factors for the development of hepatocyte apoptosis in NAFLD. ${ }^{1,6}$ Mitochondrial dysfunction may also associate with the overproduction of ROS and oxidative stress. ${ }^{6}$ In the present study, HFD did not change ROS production. However, in a previous study, we showed that individual or combined treatment with curcumin and/or capsaicin lowered ROS levels. ${ }^{7}$ In the current study, ROS levels were measured using a $\mathrm{DCFH}_{2}-\mathrm{DA}$ probe, which has been shown to react with hydrogen peroxide $\left(\mathrm{H}_{2} \mathrm{O}_{2}\right)$, peroxynitrite, lipid hydroperoxides, and the superoxide anion. ${ }^{40}$ Herein, we found that TOS levels were higher in the HFD group compared to controls. The contradictions in our ROS and TOS measurements may be due to the variations in methodology. The TOS analysis is likely a more sensitive and favorable method for the determination of OSI in a fatty liver experimental model. In the present study, HFD induced OSI levels, which decreased with curcumin and capsaicin treatment. On the other hand, TAS levels were higher with curcumin and capsaicin; this may be due to an adaptive response to the overproduction of TOS. This finding supports that capsaicin, like curcumin, has a direct effect as a radical scavenger. Similar to our results, the study of Joe et al. reported that curcumin and capsaicin diminished the production of ROS in rat peritoneal macrophages. ${ }^{15}$ The TAS assay is based on the principle that non-enzymatic antioxidants in the liver tissue reduce the dark blue-green colored 2,2'-azino-bis (3-ethylbenzothiazoline-6-sulphonic acid - ABTS) radical to its colorless reduced form. Both capsaicin and curcumin appear to balance oxidant-antioxidant status by simultaneous regulation in free radical generation and antioxidative defense augmentation.

Based on our current results, curcumin and capsaicin appear to protect HFD-induced liver injury in rats by inhibiting hepatic oxidative stress and apoptosis. The significant negative correlation between anti-apoptotic protein Bcl-2 and OSI levels confirms this assumption. In summary, curcumin and capsaicin exhibit protective effects on HFD-induced liver injury and suppress oxidative stressrelated apoptosis. The combination of the 2 spices might offer an alternative choice for protection from fatty liver injury.

\section{References}

1. Cao L, Quan XB, Zeng WJ, Yang XO, Wang MJ. Mechanism of hepatocyte apoptosis. J Cell Death. 2016;9:19-29.

2. Pessayre D, Mansouri A, Fromenty B. Nonalcoholic steatosis and steatohepatitis. V. Mitochondrial dysfunction in steatohepatitis. Am J Physiol Gastrointest Liver Physiol. 2002;282(2):193-199.

3. Dandona P, Aljada A, Chaudhuri A, Mohanty P, Garg R. Metabolic syndrome: A comprehensive perspective based on interactions between obesity diabetes and inflammation. Circulation. 2005;111(11):1448-1454. 
4. Vera-Ramirez L, Pérez-Lopez P, Varela-Lopez A, Ramirez-Tortosa M, Battino M, Quiles JL. Curcumin and liver disease. Biofactors. 2013; 39(1):88-100.

5. Yuan L, Kaplowitz N. Glutathione in liver diseases and hepatotoxicity. Mol Aspects Med. 2009;30(1-2):29-41.

6. Paradies G, Paradies V, Ruggiero FM, Petrosillo G. Oxidative stress cardiolipin and mitochondrial dysfunction in nonalcoholic fatty liver disease. World J Gastroenterol. 2014;20(39):14205-14218.

7. Öner-lyyidoğan $Y$, Tanrıkulu-Küçük $S$, Seyithanoğlu $M$, et al. Effect of curcumin on hepatic heme oxygenase 1 expression in high fat diet fed rats: Is there a triangular relationship? Can J Physiol Pharmacol. 2014;92(10):805-812.

8. Seyithanoğlu M, Öner-İyidoğan Y, Doğru-Abbasoğlu S, et al. The effect of dietary curcumin and capsaicin on hepatic fetuin-A expression and fat accumulation in rats fed on a high-fat diet. Arch Physiol Biochem. 2016;122(2):94-102.

9. Sharma SK, Vij AS, Sharma S. Mechanisms and clinical uses of capsaicin. Eur J Pharm. 2013;720(1-3):55-62.

10. Li Q, Li L, Wang F, et al. Dietary capsaicin prevents nonalcoholic fatty liver disease through transient receptor potential vanilloid 1-mediated peroxisome proliferator-activated receptor $\delta$ activation. Pflugers Arch - Eur J Physiol. 2013;465(9):1303-1316.

11. Manjunatha $\mathrm{H}$, Srinivasan K. Hypolipidemic and antioxidant effects of curcumin and capsaicin in high-fat-fed rats. Can J Physiol Pharmacol. 2007;85(6):588-596.

12. Toydemir T, Kanter M, Erboga M, Oguz S, Erenoglu C. Antioxidative, antiapoptotic, and proliferative effect of curcumin on liver regeneration after partial hepatectomy in rats. Toxicol Ind Health. 2015;31(2): 162-172.

13. Wang L, Yisong Iv, Huixiang Y, Yin L, Shang J. Curcumin prevents the non-alcoholic fatty hepatitis via mitochondria protection and apoptosis reduction. Int J Clin Exp Pathol. 2015;8(9):11503-11509.

14. Becatti M, Prignano F, Fiorillo C, et al. The involvement of Smac/DIABLO p53 NF-kB and MAPK pathways in apoptosis of keratinocytes from perilesional vitiligo skin: Protective effects of curcumin and capsaicin. Antioxid Redox Signal. 2010;13(9):1309-1321.

15. Joe B, Lokesh BR. Role of capsaicin curcumin and dietary n-3 fatty acids in lowering the generation of reactive oxygen species in rat peritoneal macrophages. Biochim Biophys Acta. 1994;1224(2):255-263.

16. Ejaz $A$, Wu D, Kwan $P$, Meydani M. Curcumin inhibits adipogenesis in 3T3-L1 adipocytes and angiogenesis and obesity in C57/BL mice. J Nutr. 2009;139(5):919-925.

17. Kang JH, Tsuyoshi G, Le Ngoc H, et al. Dietary capsaicin attenuates metabolic dysregulation in genetically obese diabetic mice. J Med Food. 2011;14(3):310-315.

18. Folch J, Lees M, Stanley GHS. A simple method for the isolation and purification of total lipids from animal tissues. J Biol Chem. 1957; 226(1):497-509.

19. Aycicek A, Iscan A, Erel O, Akcali M, Selek S. Total antioxidant/oxidant status in meningism and meningitis. Pediatr Neurol. 2006;35(6): 382-386.

20. Wang $\mathrm{H}$, Joseph JA. Quantifying cellular oxidative stress by dichlorofluorescein assay using microplate reader. Free Radic Biol Med. 1999; 27(5-6):612-616.

21. Kartkaya K, Kanbak K, Oglakci A, Burukoglu D, Ozer MC. Protective effect of calpain inhibitor N-acetyl-L-leucyl-L-leucyl-L-norleucinal on acute alcohol consumption related cardiomyopathy. Mol Biol Rep. 2014:41(10):6743-6753.
22. Tunçdemir M, Ertürküner SP, Özçelik D. Investigation of lipid peroxidation and antiapoptotic effects of zinc against liver damage in diabetic rats. Hum Exp Toxicol. 2017;36(8):813-822

23. Peng Y, Rideout DA, Rakita SS, Gower WR Jr, You M, Murr MM. Does LKB1 mediate activation of hepatic AMP-protein kinase [AMPK] and sirtuin1 [SIRT1] after Roux-en-Y gastric bypass in obese rats? J Gastrointest Surg. 2010;14(2):221-228.

24. Liu ES, Ye YN, Shin VY, et al. Cigarette smoke exposure increases ulcerative colitis-associated colonic adenoma formation in mice. Carcinogenesis. 2003;24(8):1407-1413.

25. Laemmli UK. Cleavage of structural proteins during the assembly of the head of bacteriophage T4. Nature. 1970;227(5259):680-685.

26. Soeda J, Miyagawa S, Sano K, Masumoto J, Taniguchi S, Kawasaki S. Cytochrome c release into cytosol with subsequent caspase activation during warm ischemia in rat liver. Am J Physiol Gastrointest Liver Physiol. 2001;281(4):1115-1123.

27. Donnelly $\mathrm{KL}$, Smith $\mathrm{Cl}$, Schwarzenberg SJ, Jessurun J, Boldt MD, Parks EJ. Sources of fatty acids stored in liver and secreted via lipoproteins in patients with nonalcoholic fatty liver disease. J Clin Invest. 2005;115(5):1343-1351

28. Chiang DJ, McCullough AJ. The impact of obesity and metabolic syndrome on alcoholic liver disease. Clin Liver Dis. 2014;18(1):157-163.

29. Hengartner MO. The biochemistry of apoptosis. Nature. 2000; 407(6805):770-776.

30. Ravindranath V, Chandrasekhara N. Metabolism of curcumin studies with [3H] curcumin. Toxicology. 1981;22(4):337-344

31. Shoba G, Joy D, Joseph T, Majeed M, Rajendran R, Srinivas PS. Influence of piperine on the pharmacokinetics of curcumin in animals and human volunteers. Planta Med. 1998;64(4):353-356.

32. Anand P, Kunnumakkara AB, Newman RA, Aggarwal BB. Bioavailability of curcumin: Problems and promises. Mol Pharmaceutics. 2009;4(6): 807-818.

33. Rollyson WD, Stover CA, Brown KC, et al. Bioavailability of capsaicin and its implications for drug delivery. J Control Release. 2014;196: 96-105.

34. Elmore S. Apoptosis: A review of programmed cell death. Toxicol Pathol. 2007;35(4):495-516.

35. Yu FX, Teng YY, Zhu QD, Zhang QY, Tang YH. Inhibitory effects of capsaicin on hepatic stellate cells and liver fibrosis. Biochem Cell Biol. 2014;92(5):406-412.

36. Galaly SR, Ahmed OM, Mahmoud AM. Thymoquinone and curcumin prevent gentamicin-induced liver injury by attenuating oxidative stress inflammation and apoptosis. J Physiol Pharmacol. 2014;65(6): 823-832.

37. Thompson CB. Apoptosis in the pathogenesis and treatment of disease. Science. 1995;267(5203):1456-1462.

38. Truong-Tran AQ, Grosser D, Ruffin RE. Apoptosis in the normal and inflamed airway epithelium: Role of zinc in epithelial protection and procaspase-3 regulation. Biochem Pharmacol. 2003;66(8):1459-1468.

39. Kressel M, Groscurth P. Distinction of apoptotic and necrotic cell death by in situ labelling of fragmented DNA. Cell Tissue Res. 1994; 278(3):549-556.

40. Dikalov SI, Li W, Mehranpour P, Wang SS, Zafari AM. Production of extracellular superoxide by human lymphoblast cell lines: Comparison of electron spin resonance techniques and cytochrome $\mathrm{C}$ reduction assay. Biochem Pharmacol. 2007;73(7):972-980. 